\title{
ANÁLISE DAS CARACTERÍSTICAS DOS CONTRATOS NO AGRONEGÓCIO DO BRASIL
}

\author{
ANALYSIS OF THE CHARACTERISTICS OF CONTRACTS IN AGRIBUSINESS \\ BRAZIL
}

\author{
Weimar Freire da Rocha Jr. ${ }^{1}$ \\ Maurício Vaz Lobo Bittencourt ${ }^{2}$ \\ Marcia Carla Pereira Ribeiro ${ }^{3}$
}

\section{RESUMO}

O agronegócio, ao longo dos últimos anos, passou por profundas transformações que repercutiram na coordenação e no desempenho de todos os atores participantes desse sistema. Neste sentido, este trabalho usou o arcabouço teórico da Nova Economia Institucional focado nos contratos e procurou evidenciar as salvaguardas contratuais, classificando-as segundo os atributos da transação (especificidade do ativo, frequência e incerteza). Estas serviram de base para categorizar 29 contratos do agronegócio das mais diferentes áreas e produtos. Aplicou-se a técnica estatística da análise fatorial de correspondência, procurando agrupar cada contrato em um dos três grupos supracitados. Este modelo conseguiu explicar 77,38\% do fenômeno observado com duas dimensões que representam os auto vetores. Com relação aos contratos, nesta análise, observou-se similaridade entre alguns deles principalmente, nos contratos de integração entre agroindústria e produtores, os quais buscaram resguardar as especificidades do ativo da matéria-prima. Também, há contratos que tentam resguardar a especificidade do ativo, como as relações contratuais entre agroindústrias e parceiros (aves e suínos). Já, os contratos de embalagem plástica para agroindústria e óleo semi refinado, bem como contratos de arrendamento de cana-de-açúcar, prestação de serviço e entrega de produto para a agroindústria tentam resguardar a frequência. Os contratos que visam mitigar a incerteza foram contratos de cédula de produtor rural, compra e venda de soja e laranja. Conclui-se que os contratos nem sempre são utilizados com a função de coordenadores do sistema agroindustrial, tendo, às vezes, a função de documentos formais com a finalidade de esboçar as responsabilidades entre as partes, gerando restrição de conduta e maior responsabilidade e comprometimento entre elas.

Palavras-chave: Contratos. Agronegócio. Análise fatorial de correspondência.

\footnotetext{
${ }^{1}$ Professor Associado do Curso de Graduação em Ciências Econômicas e do Programa de Stricto Sensu em Desenvolvimento Regional e Agronegócio (Mestrado e Doutorado) da Universidade Estadual do Oeste do Paraná Campus de Toledo. Rua da Faculdade, 645, CEP: 85903-000, Toledo, PR. Membro dos grupos de pesquisa GEPEC e TransLOG. E-mail: wrochajr2000@gmail.com.

2 Docente do Departamento de Economia e do programa de Pós-graduação em Desenvolvimento Econômico da. Universidade Federal do Paraná, Setor de Ciências Sociais Aplicadas. Av. Prefeito Lothario Meissner, 632, 80210-170 Curitiba, PR. Membro do grupo de pesquisa: Núcleo de Economia Internacional e Desenvolvimento Econômico (NEIDE). Email:mbittencourt@ufpr.br.

${ }^{3}$ Professora Titular de Direito Societário na PUCPR, Professora Associada de Direito Empresarial UFPR. Estágio de Pósdoutorado pela FGVSP (2005-2006). Pós-doutorado pela Universidade de Lisboa (2011/2012). Pesquisadora Convidada da Université de Montréal - CA (2007). Bolsista de Produtividade da Fundação Araucária. E-mail: mcarlaribeiro@uol.com.br
} 


\begin{abstract}
Agribusiness, over the last few years, undergone profound changes that affected the coordination and performance of all participating actors in this system. In this sense, this study used the theoretical framework of the New Institutional Economics focused on contracts and sought to highlight the contractual safeguards, classifying them according to the transaction attributes (asset specificity, frequency and uncertainty). These were the basis for categorizing 29 contracts agribusiness from different areas and products. We applied the statistical technique of factor analysis of correspondence, looking for group each contract in one of the above three groups. This model could explain $77.38 \%$ of the observed phenomenon with two dimensions representing the self vectors. With regard to contracts, in this analysis, there was similarity between some of them mainly in contracts integration between agribusiness and producers, which sought to protect the specific characteristics of the active raw material. Also, there are contracts that try to safeguard the specificity of the assets as contractual relations between agribusinesses and partners (poultry and pork). Already, plastic packaging contracts for agribusiness and semi refined oil as well as contracts of sugarcane lease, service provision and product delivery for agribusiness try to save the frequency. Contracts intended to mitigate the uncertainty were farmer ballot agreements, purchase and sale of soybeans and orange. We conclude that contracts are not always used with the agroindustrial system engineers function, and sometimes the function of formal documents for the purpose of outlining the responsibilities between the parties, generating conduct restraint and greater responsibility and commitment between they.
\end{abstract}

Keywords: Contracts. Agribusiness. Factor analysis of correspondence.

\title{
1 Introdução
}

Vem se delineando, nos últimos, anos uma busca constante por melhorias nos sistemas agroindustriais brasileiros. Essas melhorias são fruto de uma série de fatores que convergiram para o aumento da competitividade devido à abertura da economia brasileira, à busca por novos mercados, à redefinição do Estado e ao aumento da concorrência, dentre outros.

Em função desses fenômenos, os agentes econômicos que atuam e participam do sistema agroindustrial brasileiro estão se adaptando aos novos cenários e, assim, buscam melhorar seu desempenho para aumentar o lucro e para ampliar sua fatia no mercado (marketshare).

A competitividade pode ser traduzida em redução de custos, nos quais se destacam os custos de transação. Estes podem ser classificados em quatro níveis: o primeiro relacionase aos custos de construção e negociação dos contratos; o segundo envolve os custos de mensuração e monitoramento dos direitos de propriedade existentes no contrato. Este 
incorpora também os custos de observação dos contratos ao longo do tempo para seu desempenho e atende às expectativas das partes que fizeram a transação. O terceiro engloba os custos de manutenção e execução dos contratos internos e externos da firma. O quarto e último nível refere-se aos custos de adaptação pelos quais passam os agentes com as mudanças ambientais (FARINA, 1999). Por isso, quanto mais rápida for a adaptação, menos custos de transação existirão, resultando em lucros maiores. Os sistemas eficientes são a consequência de um conjunto de instituições que fornecem, com baixo custo, as medidas e os meios para que os contratos sejam cumpridos, sendo o contrário também verdadeiro (OLIVEIRA, 1998).

Nessa concepção, a unidade de análise passa a ser a transação entre os agentes econômicos e o conceito de firma é expandido, pela ótica coaseana, como um local onde se gerenciam as redes de contratos. Ademais, na transação, identificam-se três princípios: o conflito, a mutualidade e a ordem, pois na transação eles estão presentes na estrutura de governança que a ordena, no conflito que ocorre entre as partes para a distribuição do lucro e na oportunidade de ganhos mútuos entre elas (WILLIAMSON, 2000).

Os custos de transação, então, irão definir as estruturas de governança adotadas pelo sistema, as quais se configuram entre a integração vertical, num extremo, e o mercado, no outro, existindo inúmeras possibilidades entre os dois polos.

Os contratos passam a ser uma modalidade de estrutura de governança adotada pelos agentes econômicos no agronegócio, a qual poderá deter uma coordenação mais compatível com suas particularidades. Para isso, será necessária a elaboração de contratos específicos que atendam às mais variadas demandas existentes no sistema agroindustrial, com o objetivo de facilitar as trocas de produtos ou serviços entre esses agentes, além de resguardar as partes envolvidas.

Nesse sentido, o estudo das redes de contratos que existem dentro do sistema agroindustrial brasileiro torna-se relevante para a elaboração de políticas públicas e estratégias empresariais.

O problema levantado por esta pesquisa reside na seguinte indagação: Quais seriam as características contratuais existentes dentro dos sistemas agroindustriais brasileiros? A resposta para esse questionamento ganha importância quando se observa que, em termos do Produto Interno Bruto (PIB), o sistema agroindustrial brasileiro passou de 27\%, em 1994, para $30 \%$ em 2004, no em que foram gerados $37 \%$ dos empregos e $43 \%$ das exportações 
brasileiras. Ademais, apesar das significativas barreiras tarifárias e não-tarifárias enfrentadas no comércio externo, o agronegócio brasileiro é um caso de sucesso internacional, pois responsabiliza-se por $82 \%$ do suco de laranja distribuído no mundo, $29 \%$ do açúcar-de-cana consumido, $28 \%$ do café em grão, $44 \%$ do café solúvel, $23 \%$ do tabaco, por $38 \%$ do mercado internacional de soja; e, ainda, é líder mundial nas exportações de álcool, couro curtido, calçado de couro e carnes bovinas e de frango. Isso faz com que o conjunto de atividades econômicas que formam o agronegócio dê importantes contribuições para o saldo comercial externo do País (RODRIGUES, 2004). Ainda, segundo dados mais recentes divulgados pelo Ministério da Agricultura Pecuária e Abastecimento (MAPA) em 2010, o Brasil é um dos principais produtores e fornecedores de matérias-primas para o mundo: é o maior produtor e exportador de açúcar, café e suco de laranja; segundo produtor de soja, tabaco, carne bovina e etanol; terceiro maior produtor de aves: quarto maior produtor de milho e suínos; maior exportador de carne bovina, tabaco, etanol e aves; e, segundo maior exportador em soja.

A busca pela compreensão da questão exposta acima e da importância que o agronegócio brasileiro assume para o desenvolvimento, geração de renda e emprego para a sociedade, justificam o estudo que esse trabalho pretende desenvolver.

De mais a mais o objetivo deste estudo será analisar 29 contratos do agronegócio brasileiro, os quais serão categorizados segundo os atributos de transação (especificidade do ativo, frequência e incerteza), além de analisar suas salvaguardas. Para tanto, o trabalho será subdividido em quatro partes. Nesta primeira, a introdução, o conteúdo abarca uma visão panorâmica do agronegócio brasileiro, o problema e objetivo. A segunda parte contará com a revisão de literatura, para, a seguir, ser apresentado o procedimento metodológico. Após, os resultados e discussões inalizando-secom as conclusões do estudo.

\section{Revisão de literatura}

\subsection{0 contrato}

A partir do momento que os pressupostos dos agentes econômicos são relaxados e estes são oportunistas e limitadamente racionais, os custos de transação são detectados, existem informações imperfeitas e assimétricas, as instituições ganham destaque e devem estar vinculadas à análise econômica, uma vez que são elementos que delimitarão as ações 
destes indivíduos, consequentemente, influenciarão suas condutas, por isso são consideradas relevantes na análise.

Por isso, os contratos são tratados com grande ênfase, têm um papel de destaque na NEI, uma vez que cada estrutura de governança detém uma forma de combinação entre os agentes que minimizam os custos de transação, e, em determinadas circunstâncias, o contrato pode ser uma estrutura de governança mais compatível com os atributos de transação, proporcionando maior eficiência ao sistema, pois sua função é facilitar as trocas de produtos ou serviços entre esses agentes.

A estrutura de governança contrato é tão antiga que no museu de egiptologia de Turim, Itália, fica em exposição um contrato descrito em hieróglifos de compra/venda de imóvel. Por este documento pode-se perceber que esta estrutura de governança era usada na vida cotidiana do povo egípcio há milênios e continua sendo usada nos dias de hoje.

Segundo Gomes (2002), contrato é um acordo bilateral de coordenação de condutas, ou seja, é através de um documento acordado entre as partes que suas condutas serão monitoradas durante um período de tempo. É também um ato ou negócio bilateral que envolve duas ou mais partes.

O contrato é um conceito jurídico que abarca uma série de princípios e regras do Direito com reflexo nas relações socioeconômicas instrumentalizando as transações, sendo uma veste jurídica formal para uma atividade econômica (ROPPO, 1977).

O contrato deve estar em conformidade com seu fim e com seu conteúdo lógico, ético, sociológico, econômico e político-social. Assim, seus tipos esquematizados na lei serão estudados como instrumento jurídico para a constituição, transmissão e extinção de deveres na área econômica. Tem também a característica de ser um facilitador da circulação de mercadorias e serviços, direcionando este fluxo para as partes mais interessadas em obtê-los, de forma que existe a liberdade de escolha entre as partes a fim de selecionar quem será o agente econômico contratado e a livre negociação dos termos no momento em que se pactuarem os interesses (ARAÚJO, 2007).

No Brasil contemporâneo, após a reformulação da constituição de 1988 foram designadas novas funções ao contrato tirando seu foco em torno das características individuais e dando contornos mais sociais como posteriormente será discutido (LUPION, 2011).

Zylbersztajn (2005) destaca os seguintes aspectos relacionados aos contratos: a) incompletude: característica principal dos contratos que advém da incapacidade de preverem- 
se todos os eventos futuros; b) custos: relacionado a todas as etapas de montagem de um contrato, incluindo os mecanismos para a solução dos conflitos e a punição de comportamentos indesejados; c) duração: os contratos podem ser temporários ou indeterminados. $\mathrm{Na}$ presença de ativos específicos as partes buscam prazo mais longo, garantindo, assim, o retorno sobre o investimento realizado.

Segundo Ribeiro e Galeski Junior, (2009), a ausência de previsibilidade como elemento para a aplicação dos princípios interventivos no contrato esbarra na essência da formação contratual devido a racionalidade limitada, a qual vai ao encontro do item a), relacionado por Zylbersztajn (2005). A incompletude contratual segue a proposição de Zylbersztajn (2005), Ribeiro e Galeski Junior (2009) e Williamson (2002), cujos pressupostos comportamentais do agente econômico são a racionalidade limitada e o oportunismo. Além destes existe a indefinição do ambienteem que os agentes estão inseridos, os quais são influenciados por um número considerável de variáveis econômicas, sociais, demográficas tecnológicas e governamentais que fazem com que haja uma constante incerteza e podem motivar o oportunismo. Isto amplia o grau de incompletude contratual e torna os contratos complexos, uma vez que são criadas salvaguardas ex-ant (na tentativa de coibir quebra contratuais) e ex-post, após a verificação de uma falha contratual, a qual só será complementada na confecção do próximo contrato, mas nunca o será de forma plena. Assim, a variável tempo é outro elemento relevante que também influenciará os contratos.

Apesar da limitação, o contrato tem a peculiaridade de ser uma estrutura de governança que, em determinadas circunstâncias, pode coordenar de forma mais eficiente, descrevendo um relacionamento idiossincrático "sob medida" para os contratantes, capacitando-os para suprir as demandas das partes de forma não ótima, mas razoável, sem a ideia romântica de ser maximizadora, mas apenas satisfatória (Williamson, 2002).

Este relacionamento bilateral (contrato) traduzido na unidade analítica transação contém os princípios de conflito, mutualidade e ordem, os quais são organizados e equilibrados no contrato para uma melhor compreensão das demandas de cada agente, relacionando-as de maneira satisfatória, melhor que outras estruturas de governança e.g. mercado, que podem conter efeitos de interesse difusos e não atenderem de maneira eficiente os interesses dos agentes pelo incentivo; também a integração vertical pornão oferecer um grau de satisfação entre os agentes econômicos por tornar o controle um tanto elevado a ponto de não satisfazer os agentes econômicos.Assim, a estrutura de governança contrato é uma 
situação intermediária híbrida que abarca características que conseguem, dentro de um ambiente institucional, atender os interesses dos agentes que estão se relacionando e ordenar a transação.

A estrutura de governança contrato, além de ter o propósito de formalizar e explicitar informações e restrições com a finalidade de harmonizar as partes tem outra característica interessante que é a formalização das condutas no sentido de registrar a forma como os agentes devem coordenar seu negócio, assume, assim, a função de uma lista de checagem que deve ser seguida (lembrando e reiterando as condutas) e, pela sua formalização, estabelece a continuidade das práticas estabelecidas.

No entanto, existem outros pontos que são interessantes, como os apresentados por Tirole (2009) que elaborou a concepção de que um contrato incompleto e uma heurística cognitiva limitada desencadeiam ineficiências provocadas pela conjugação destes dois fatores e levanta evidências de que esta incompletude contratual ocorre no seio das organizações onde os agentes econômicos atuam. Isto, devido ao fato de os indivíduos não receberem incentivos para a elaboração de um contrato mais perfeito possívelem decorrência dos caminhos de dependência da organização, pela estratégia para permanecer na organização e pelo incentivo propriamente dito. Todos estes fatores proporcionam um contrato ineficiente com a possibilidade de gerar reféns e seek-renting, prejudicando as partes envolvidas.

Para McDonald et al. (2004), houve sensível mudança nas estruturas de governança a partir da década de 60, do século XX. Nos Estados Unidos houve a migração da estrutura de governança via mercado pra a via contratos, a qual tem a possibilidade de limitar o nível de risco, reduzir os custos ou a combinação dos dois numa transação. Os contratos podem reduzir sensivelmente uma série de riscos, por permitir que os agentes se adequem a suas necessidades comuns e, assim, criem um ambiente propício para a redução de custos de transação.

Um segmento que utiliza muito o contrato é a agricultura e está relacionado com o arrendamento de terras. Fukunaga e Huffman (2009) mostram que este tipo de estudo vem recebendo a atenção de economistas desde o século XIX. No trabalho desenvolvido por estes pesquisadores, eles modelaram um conjunto de variáveis que tratavam das situações socioeconômicas, características dos domicílios de proprietários e arrendatários de terras, assim como quantidades produzidas e rendimentos nas atividades agrícolas. 
Para Zylbersztajn (2005), os agricultores se organizam horizontalmente sob a forma de relações contratuais, visando economias de escala, de rede, com a finalidade de adicionar valor seletivamente e ampliar a coordenação com a empresa processadora. Também a organização vertical dos produtores é verificada na agricultura e na pecuária onde os contratos também são estruturas de coordenação significativas.

Kavløy e Olsen (2009) desenvolvem um modelo que possibilita identificar dois sutis caminhos para atingir a execução dos propósitos contratuais: as instâncias superiores ou a interação entre as partes pela repetição das relações. Desta forma, este modelo endogeniza a verificabilidade e o grau de incompletude contratual. $\mathrm{O}$ equilíbrio do grau de incompletude depende do nível de verificação tecnológica, a qual será influenciada pela capacidade qualitativa da instância superior em julgar os processos, sua habilidade e sua prescrição em analisar os recursos.

\section{Procedimento metodológico}

A análise feita neste estudo pode ser considerada como descritiva, cujo objetivo primordial é a descrição das características de determinada população ou fenômeno ou, ainda, o estabelecimento de relações entre variáveis (GIL, 2000); explicativa, pois a análise da simples identificação da existência de relações entre as variáveis pretende discutir a natureza dessa relação, ou seja, quais são as influências que as teorias dos contratos exercem sobre a formulação e elaboração de um contrato.

Dessa forma, em função do caráter descritivo (aproximando-se do explicativo), e à guisa de uma revisão bibliográfica acerca da Nova Economia Institucional (NEI) e da análise fatorial de correspondência (AFC) serão avaliados os elementos considerados importantes para a caracterização dos atributos da transação (a especificidade do ativo, incerteza e frequência ) na explicação da diversidade contratual.

Para o desenvolvimento do estudo foram utilizados 29 contratos de sistemas agroindustriais, os quais produziram uma tabela de contingência que tem na linha os contratos e na coluna os principais atributos de transação encontrados em cada contrato (Tabela 1). 
Tabela 1 - Contratos e atributos a transação

\begin{tabular}{|c|c|c|c|c|c|c|c|}
\hline & Contrato & $\begin{array}{l}\text { Especificidade } \\
\text { física }\end{array}$ & $\begin{array}{l}\text { Outra } \\
\text { especificidade }\end{array}$ & $\begin{array}{l}\text { Frequência } \\
\text { Moderada }\end{array}$ & $\begin{array}{l}\text { Frequência } \\
\text { intensa }\end{array}$ & $\begin{array}{l}\text { Alto } \\
\text { risco }\end{array}$ & $\begin{array}{l}\text { Baixo } \\
\text { risco }\end{array}$ \\
\hline 1 & $\begin{array}{l}\text { Importação de } \\
\text { equipamento } \\
\text { agroindústria }\end{array}$ & 1 & 0 & 1 & 0 & 0 & 1 \\
\hline 2 & $\begin{array}{ll}\text { Ampliação } & \text { de } \\
\text { frigorifico } & \text { de } \\
\text { aves } & \end{array}$ & 1 & 0 & 1 & 0 & 0 & 1 \\
\hline 3 & $\begin{array}{ll}\text { Aquisição } & \text { de } \\
\text { matrizes } & \text { de } \\
\text { frango } & \end{array}$ & 1 & 0 & 0 & 1 & 1 & 0 \\
\hline 4 & $\begin{array}{lr}\text { Aquisição } & \text { de } \\
\text { matrizes } & \text { e } \\
\text { machos } & \end{array}$ & 1 & 0 & 0 & 1 & 1 & 0 \\
\hline 5 & $\begin{array}{l}\text { Exportação } \\
\text { frango }\end{array}$ & 0 & 1 & 0 & 1 & 1 & 0 \\
\hline 6 & $\begin{array}{l}\text { Manutenção } \\
\text { industrial }\end{array}$ & 0 & 1 & 1 & 0 & 1 & 0 \\
\hline 7 & $\begin{array}{l}\text { Parceria } \\
\text { avicultor }\end{array}$ & 1 & 0 & 0 & 1 & 0 & 1 \\
\hline 8 & $\begin{array}{l}\text { Parceria1 } \\
\text { avicultor } 2\end{array}$ & 1 & 0 & 0 & 1 & 0 & 1 \\
\hline 9 & $\begin{array}{l}\text { Transporte } \\
\text { agroindústria }\end{array}$ & 0 & 1 & 0 & 1 & 1 & 0 \\
\hline 10 & Embalagens & 0 & 1 & 0 & 1 & 0 & 1 \\
\hline 11 & Certificadora & 1 & 0 & 0 & 1 & 1 & 0 \\
\hline 12 & $\begin{array}{l}\text { Compra de } \\
\text { equipamento } \\
\text { nacional }\end{array}$ & 1 & 0 & 1 & 0 & 1 & 0 \\
\hline 13 & $\begin{array}{l}\text { Parceria suínos } \\
\text { terminação } 1\end{array}$ & 1 & 0 & 0 & 1 & 1 & 0 \\
\hline 14 & Suínos UPL & 1 & 0 & 0 & 1 & 1 & 0 \\
\hline 15 & $\begin{array}{l}\text { Parceria suínos } \\
\text { terminação } 2\end{array}$ & 1 & 0 & 0 & 1 & 1 & 0 \\
\hline 16 & $\begin{array}{l}\text { Parceria suínos } \\
\text { terminação } 3\end{array}$ & 1 & 0 & 0 & 1 & 1 & 0 \\
\hline 17 & $\begin{array}{l}\text { Parceria suínos } \\
\text { terminação } 3\end{array}$ & 0 & 1 & 1 & 0 & 0 & 1 \\
\hline 18 & Fumo & 0 & 1 & 0 & 1 & 1 & 0 \\
\hline 19 & Óleo & 0 & 1 & 0 & 1 & 0 & 1 \\
\hline 20 & Cpr & 0 & 1 & 1 & 0 & 0 & 1 \\
\hline 21 & Cana 1 & 0 & 1 & 0 & 1 & 0 & 1 \\
\hline 22 & Cana 2 & 0 & 1 & 1 & 0 & 0 & 1 \\
\hline 23 & Cana 3 & 0 & 1 & 1 & 0 & 0 & 1 \\
\hline 24 & Cana 4 & 0 & 1 & 0 & 1 & 0 & 1 \\
\hline 25 & Soja & 0 & 1 & 1 & 0 & 0 & 1 \\
\hline 26 & Mandioca & 0 & 1 & 1 & 0 & 0 & 1 \\
\hline 27 & Frutas 1 & 1 & 0 & 0 & 1 & 0 & 1 \\
\hline 28 & Frutas 2 & 1 & 0 & 0 & 1 & 0 & 1 \\
\hline 29 & Cachaça & 1 & 0 & 1 & 0 & 1 & 0 \\
\hline
\end{tabular}


O embasamento teórico foi desenvolvido a partir de uma revisão da literatura sobre os principais conceitos e/ou aplicações da estatística AFC, em que serão revisitados autores como: Carrol et al. (1986); Carrol et al. (1989); Greenacre (1989); Hoffman e Franke (1986), Benzécri et al. (1973); e,Kaciak e Louviere (1990).

A análise fatorial é uma técnica de análise multivariada que se baseia na obtenção de fatores e escores através de variâncias e covariâncias (MORVAN et al., 1996). A AFC é uma técnica de análise exploratória utilizada para estudar as associações entre duas ou mais variáveis categóricas, permitindo a visualização das relações entre linhas e colunas num mesmo espaço gráfico (SILVA; VERDINELLI, 1997). Por meio da AFC, procura-se encontrar as relações recíprocas, associações e oposições entre variáveis ou entre objetos e variáveis (BENZÉCRI et al., 1973). Com a AFC, podem-se estudar as tabelas de frequência cruzada, conhecidas como tabelas de contingência, as matrizes nas quais as linhas representam objetos ou indivíduos e as colunas variáveis, com uma ou várias modalidades.

Existe uma grande semelhança entre a análise fatorial de correspondência e a análise de componentes principais, que é o método fatorial mais comum. No entanto, uma das diferenças reside na análise de componentes principais, cujos dados são quantitativos, enquanto que na AFC são qualitativos ou quantitativos codificados, ou dados contínuos discretizados, com a restrição de que sejam positivos (VERDINELLI, 1980). Como nos outros métodos fatoriais, na AFC pode-se reduzir o espaço de representação sem perdas substanciais de informação.

A análise de correspondência, em sua essência, é um algoritmo que, por manipulações algébricas, a partir de uma tabela de contingência, permite uma visão simplificada da realidade multidimensional. Possui como referência a hipótese de interdependência entre as variáveis. E pode-se, também, considerar essa análise como altamente flexível com os dados requisitados (HOFFMAN; FRANKE, 1986).

De fato, na vida real trabalha-se com conjuntos de variáveis categóricas com grande número de modalidades que possuem inter-relações difíceis de serem entendidas. A utilização da AFC torna possível a interpretação das variáveis sob as representações geométricas, revelando-se a estrutura dos dados de forma ótima, sem a necessidade de assumir modelos ou distribuições conhecidas. Nesse contexto, a AFC é uma técnica de análise exploratória de dados que possibilita gerar hipóteses a partir das associações e oposições estudadas. 
Nesse sentido, Nogueira (2003) afirma que a AFC é um método que consiste em duas etapas básicas. Na primeira, efetua-se o cálculo da medida de associação por meio da distribuição da estatística do qui-quadrado para padronizar os valores das frequências e formar a base para as associações. A partir de uma tabela de contingência, calculam-se as frequências esperadas e o valor de qui-quadrado para cada célula, considerando-se as diferenças entre as frequências observadas e as esperadas ao quadrado. A padronização é necessária porque é mais comum a ocorrência de diferenças em células com altas frequências do que naquelas com valores pequenos.

$\mathrm{Na}$ segunda etapa, é criado um mapa perceptual; os valores de similaridade (quiquadrado) oferecem uma medida padronizada da associação. Com essas medidas, a análise de correspondência cria uma medida em distância métrica e cria dimensões ortogonais sobre as quais as categorias podem ser projetadas, de forma a representar o grau de associação dado pelas distâncias do valor qui-quadrado (NOGUEIRA, 2003).

Tecnicamente, os planos fatoriais ou inerciais de representação (subespaços vetoriais) permitem mostrar os relacionamentos entre linhas e colunas da tabela (em nosso caso, contratos e atributos da transação). As linhas e colunas são representadas por um ponto - determinado pelo vetor de frequências de suas células - num espaço euclidiano, e as distâncias entre os pontos, ou entre esses e o centro de gravidade - a origem de coordenadas são medidas em distâncias de $\chi^{2}$ (qui-quadrado). A contribuição à inércia da nuvem dos pontos-variáveis se relaciona com sua distância em relação ao centro de coordenadas; assim, quanto mais distante do centro, maior a sua contribuição.

De acordo com Carrol et al. (1986), dada uma matriz de frequência $F$, que tem os perfis marginais linha e marginais coluna representados em duas matrizes diagonais $R$ e $C$, a primeira transformação ocorre na normalização da matriz $F$, quando da geração de um nova matriz $H$, da seguinte forma:

$$
H=R^{-1 / 2} F C^{-1 / 2}
$$

O segundo passo é encontrar o valor singular de decomposição da matriz $H$, assim denotado:

$$
H=P \Delta Q
$$

onde $P^{\prime} P=Q^{\prime}, Q=I$ e $\Delta$ é diagonal. Nesta transformação, o primeiro autovetor de solução trivial não é considerado. 
O terceiro e último passo define a configuração das coordenadas linhas e colunas, respectivamente, $X$ e $Y$, após reduzir as dimensões matriciais.

$$
\begin{aligned}
& X=R^{-1 / 2} P \Delta \\
& Y=C^{-1 / 2} Q
\end{aligned}
$$

Os conjuntos de coordenadas transformadas em $X$ e $Y$ representam o conjunto de interesses em trabalhos que abordem a AFC e permitem a utilização de um mesmo espaço gráfico de linhas e colunas. Entretanto, cada conjunto deve ser analisado separadamente (HOFFMAN; FRANKE, 1986). A escala tradicional com as coordenadas $X$ e $Y$ não permite esse tipo de interpretação.

\section{Resultados e discussões}

Os contratos são estruturas de governança usadas corriqueiramente dentro do sistema econômico capitalista, no entanto atendem a outras finalidades, como, por exemplo, pode ser mero instrumento de memória entre os agentes que estão se relacionando, além da coordenação como ficará patente ao longo dos próximos parágrafos.

Foram analisados vinte e nove contratos dos mais variados sistemas agroindustriais, os quais vão ao encontro de Zylbersztajn (2005) e McDonalds et al. (2011) e mostram que o número de contratos utilizados no agronegócio vem se expandindo nos últimos anos.

Utilizou-se da metodologia proposta pelo uso do modelo estatístico da análise fatorial de correspondência, no qual os contratos foram classificados segundo os critérios quanto às principais salvaguardas que seriam protegidas no contrato. Para isso, o critério utilizado foram os atributos da transação, classificando-se os contratos e dando destaque:às especificidades dos ativos, à frequência e às incertezas. Estes atributos foram subdivididos em especificidade do ativo alta e baixa, frequência elevada ou moderada, e baixa e alta incerteza.

A partir desta classificação foi possível separar os contratos e,utilizando-sedestes critérios, aplicar o modelo estatístico para as devidas análises.

A Tabela 2 apresenta os valores da inércia total, que é definida como a divisão entre o Chi-quadrado $\left(\chi^{2}\right)$ e o número de observações totais de ocorrência do fenômeno. No caso, foram observados em cada contrato 3 ocorrências, perfazendo o valor de 87, que gerou o valor total da inércia igual a 1 . A primeira coluna apresenta o número de dimensões que 
reconstroem todas as observações feitas nos contratos, gerando assim duas dimensões que explicam $77,38 \%$ do fenômeno analisado.

Tabela 2 - Autovalores e Inércia para as dimensões

\begin{tabular}{llllll}
\hline Dimensões & $\begin{array}{l}\text { Valores } \\
\text { singulares }\end{array}$ & Autovalores & $\begin{array}{l}\text { Percentual } \\
\text { da inércia }\end{array}$ & $\begin{array}{l}\text { Percentual } \\
\text { acumulado }\end{array}$ & $\begin{array}{l}\text { Valores das } \\
\text { estatísticas } \chi^{2}\end{array}$ \\
\hline 1 & 0,720149 & 0,518614 & 51,86142 & 51,8642 & 45,11944 \\
2 & 0,505175 & 0,255202 & 25,52019 & 77,3816 & 22,20257 \\
\hline \multicolumn{4}{l}{ Total da inércia $=1,000000$} & Chi-quadrado $\left(\chi^{2}\right)=87,0000$ & \\
\hline
\end{tabular}

Dando continuidade à análise da Tabela 2, a primeira dimensão extrai a maioria das informações (isto é, tem o autovalor mais elevado) e a segunda extrai mais informações, mas não atinge a totalidade que seria de $100 \%$. Dessa forma, a análise realizada sobre os contratos (objeto) e os atributos da transação (caracteres) mostra que a primeira dimensão extrai $51,86 \%$ da inércia total e a segunda dimensão aumenta a inércia "explicada" em 25,52\%, ou seja, estas duas dimensões explicam juntas 77,38\% do total da inércia. Assim, apresenta-se uma verificação razoável à análise bidimensional. A coluna dois representa os valores singulares obtidos pela decomposição do valor singular generalizado. A coluna três apresenta os autovalores que são os quadrados dos valores singulares. A soma dos autovetores computará a inércia total, a qual representa a quinta coluna e, se as demais dimensões fossem incluídas no estudo totalizariam $100 \%$ da inércia total.

Nas Tabelas 3 e 4 são apresentadas as colunas que representam as coordenadas de cada um dos 29 contratos e dos atributos da transação discriminados que foram plotados nos eixos $\mathrm{X}$ e $\mathrm{Y}$, as quais representam respectivamente as dimensões 1 e 2, a massa, a qualidade dos dados e os cossenos quadrados das dimensões 1 e 2 . 
Tabela 3 - Relação dos 29 contratos com as coordenadas e cossenos quadrados das dimensões 1 e 2 e respectivas massa e qualidade dos dados

\begin{tabular}{|c|c|c|c|c|c|c|c|}
\hline Contratos & Dimensão1 & Coss2 Dim. 1 & Dimensão2 & Coss2 Dim. 2 & Inércia & Massa & Qualidade \\
\hline 1 & 0,396 & 0,139 & 0,801 & 0,568 & 0,039 & 0,034 & 0,707 \\
\hline 2 & $-0,957$ & 0,990 & 0,801 & 0,560 & 0,039 & 0,034 & 0,996 \\
\hline 3 & $-0,957$ & 0,990 & 0,075 & 0,006 & 0,032 & 0,034 & 0,996 \\
\hline 4 & $-0,957$ & 0,085 & 0,075 & 0,006 & 0,033 & 0,034 & 0,416 \\
\hline 5 & $-0,287$ & 0,102 & $-0,567$ & 0,331 & 0,033 & 0,034 & 0,220 \\
\hline 6 & 0,366 & 0,085 & 0,393 & 0,118 & 0,045 & 0,034 & 0,117 \\
\hline 7 & $-0,258$ & 0,085 & $-0,160$ & 0,032 & 0,027 & 0,034 & 0,117 \\
\hline 8 & $-0,258$ & 0,085 & $-0,160$ & 0,032 & 0,027 & 0,034 & 0,416 \\
\hline 9 & $-0,287$ & 0,204 & $-0,567$ & 0,331 & 0,033 & 0,034 & 0,975 \\
\hline 10 & 0,412 & 0,990 & $-0,801$ & 0,771 & 0,029 & 0,034 & 0,996 \\
\hline 11 & $-0,957$ & 0,073 & 0,075 & 0,006 & 0,032 & 0,034 & 0,918 \\
\hline 12 & $-0,303$ & 0,990 & 1,035 & 0,845 & 0,044 & 0,034 & 0,996 \\
\hline 13 & $-0,957$ & 0,990 & 0,075 & 0,006 & 0,032 & 0,034 & 0,996 \\
\hline 14 & $-0,957$ & 0,990 & 0,075 & 0,006 & 0,032 & 0,034 & 0,996 \\
\hline 15 & $-0,957$ & 0,990 & 0,075 & 0,006 & 0,032 & 0,034 & 0,996 \\
\hline 16 & $-0,957$ & 0,085 & 0,075 & 0,006 & 0,032 & 0,034 & 0,117 \\
\hline 17 & 1,065 & 0,967 & 0,159 & 0,022 & 0,040 & 0,034 & 0,117 \\
\hline 18 & $-0,287$ & 0,085 & $-0,567$ & 0,331 & 0,033 & 0,034 & 0,416 \\
\hline 19 & 0,412 & 0,204 & $-0,801$ & 0,771 & 0,044 & 0,034 & 0,975 \\
\hline 20 & 1,065 & 0,967 & 0,159 & 0,022 & 0,044 & 0,034 & 0,996 \\
\hline 21 & 0,412 & 0,204 & $-0,801$ & 0,771 & 0,029 & 0,034 & 0,918 \\
\hline 22 & 1,065 & 0,967 & 0,159 & 0,022 & 0,044 & 0,034 & 0,996 \\
\hline 23 & 1,065 & 0,967 & 0,159 & 0,022 & 0,044 & 0,034 & 0,996 \\
\hline 24 & 0,412 & 0,204 & $-0,801$ & 0,771 & 0,029 & 0,034 & 0,996 \\
\hline 25 & 1,065 & 0,967 & 0,159 & 0,022 & 0,044 & 0,034 & 0,996 \\
\hline 26 & 1,065 & 0,967 & 0,159 & 0,022 & 0,044 & 0,034 & 0,989 \\
\hline 27 & $-0,258$ & 0,085 & $-0,160$ & 0,032 & 0,027 & 0,034 & 0,117 \\
\hline 28 & $-0,258$ & 0,085 & $-0,160$ & 0,032 & 0,027 & 0,034 & 0,117 \\
\hline 29 & $-0,303$ & 0,073 & 1,035 & 0,845 & 0,044 & 0,034 & 0,918 \\
\hline
\end{tabular}


Tabela 4 - Atributos da transação discriminados com as coordenadas e cossenos quadrados das dimensões 1 e 2 e respectivas massa e qualidade dos dados

\begin{tabular}{llllllll}
\hline $\begin{array}{l}\text { Atributos } \\
\text { da } \\
\text { transação }\end{array}$ & Dimensão1 & $\begin{array}{l}\text { Coss }^{2} \\
\text { Dim. 1 }\end{array}$ & Dimensão2 & $\begin{array}{l}\text { Coss }^{2} \\
\text { Dim. 2 }\end{array}$ & $\begin{array}{l}\text { Inércia } \\
\text { Relativa }\end{array}$ & Massa & Qualidade \\
\hline $\begin{array}{l}\text { Esp física } \\
\text { Outra }\end{array}$ & $-0,698$ & 0,522 & 0,469 & 0,236 & 0,161 & 0,172 & 0,758 \\
$\begin{array}{l}\text { espec } \\
\text { Freq }\end{array}$ & 0,748 & 0,522 & $-0,503$ & 0,236 & 0,172 & 0,161 & 0,758 \\
$\begin{array}{l}\text { moderada } \\
\begin{array}{l}\text { Freq } \\
\text { intense }\end{array}\end{array}$ & 0,876 & 0,469 & 0,404 & 0,498 & 0,207 & 0,126 & 0,968 \\
$\begin{array}{l}\text { Incerteza } \\
\text { alta }\end{array}$ & $-0,833$ & 0,469 & 0,247 & 0,498 & 0,126 & 0,207 & 0,968 \\
$\begin{array}{l}\text { Incerteza } \\
\text { baixa }\end{array}$ & 0,677 & 0,564 & 0,022 & 0,031 & 0,183 & 0,149 & 0,595 \\
\hline & 0,564 & 0,018 & 0,031 & 0,149 & 0,184 & 0,595 \\
\hline
\end{tabular}

Nas Tabelas 3 e 4 são apresentadas na primeira e na terceira coluna as coordenadas nos eixos da primeira e da segunda dimensão, estas representaram os contratos e os atributos na Figura 1. As colunas onde estão representadas os cossenos quadrados da dimensão 1 e 2 informam o ajuste de cada ponto com os eixos das dimensões 1 e 2 . Os valores de Cosseno ${ }^{2}$ somados através das duas dimensões são iguais ao valor total da qualidade. A contribuição relativa de cada ponto à inércia para cada dimensão está na coluna inércia relativa (destaca-se que os autovalores representam as inércias associadas a cada dimensão). No caso específico, a maior inércia relativa ficou com os contratos 6 , com 0,045 e a menor ficou com os contratos 27 e 28 , com 0,027 . Os valores da inércia relativa representam a proporção da inércia total, a qual explica o ponto respectivo. Um ponto pode ter a sua representação bem definida, mas mesmo assim não contribui com a inércia total. A inércia relativa é a contribuição de cada ponto.

A análise do termo massa representa as entradas na tabela de contingência em dois sentidos de frequências relativas (isto é, cada entrada é dividida pela soma de todasas entradas na tabela). Os resultados da AFC são medidas válidas, se as entradas na tabela não forem frequências, mas alguma outra medida da correspondência, tais como a associação, similaridade, ou outra, devendo a soma de todas as entradas na tabela de frequências relativas seja igual a 1.Na terminologia da análise da correspondência, os totais de linha e os totais de coluna da tabela de frequências relativas são chamados, respectivamente, a massa da linha e 
massa da coluna. A massa representa a proporção ponto na linha e coluna. A última coluna da Tabela 3 identifica a qualidade de um ponto, a qual é definida como a relação do quadrado da distância do ponto da origem no número escolhido das dimensões sobre a distância quadrado da origem no espaço definido pelo número máximo das dimensões (medido pela estatística do chi-quadrado). Como se pode observar pelas Tabelas 3 e 4,tanto os pontos nas linhas como nas colunas são representados na solução bidimensional; a qualidade para todos os pontos seria igual a 1 se todas as dimensões fossem analisadas, como apenas duas estão sendo trabalhadas existem variações.

Os valores relativos da inércia pertencem à proporção da inércia total "explicada" pelo ponto respectivo. Note que um ponto pode bem ser representado em uma solução particular, mas pode não contribuir muito à inércia total.

Analisando-se a Figura 1, é possível iniciar a classificação segundo os atributos da transação. Cabe destacar que as relações entre os contratos e atributos da transação se estabelecem via os dois eixos das dimensões 1 e 2. A classificação se deu em função de um melhor ajuste entre o contrato e o eixo das dimensões que representam os autovetores , ocorrendo da mesma forma com os atributos. Com isto é possível, num mesmo gráfico, estabelecer a relação entre o contrato e o atributo da transação pela variável interveniente eixo das dimensões.

Figura 1 - Gráfico com os 29 contratos e as especificidades dos ativos em um espaço bidimensional.

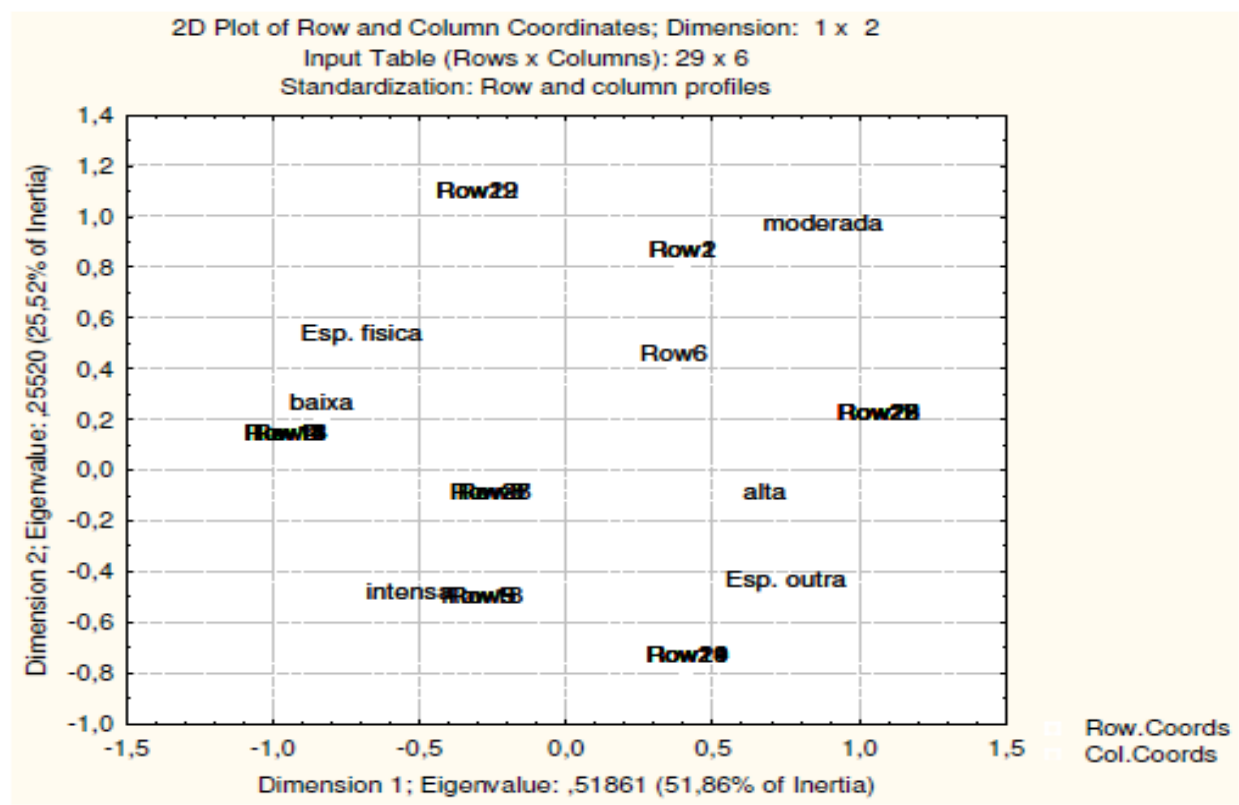


Ao analisarem-se os contratos observa-se que eles tiveram as especificidades dos ativos melhor ajustados e a representação do eixo um das abcissas foram:

Os contratos 7 e 8 referem-se à parceria entre avicultor e agroindústria. Esta denominação diz respeito à forma de coordenação existente entre as partes: a agroindústria fornece insumos, assistência técnica e o avicultor infraestrutura e mão de obra para a criação de frangos. A especificidade neste contrato é temporal, uma vez que o prazo de entrega deverá ser efetivado em um determinado prazo, isto é, a idade dos animais pode variar entre 35 a 60 dias. Após a entrega do lote, o avicultor deverá deixar o aviário pronto para receber outro lote, entre 4 a 30 dias depois da saída dos últimos animais.

O mesmo ocorre com os contratos 13, 15 e 16 que tratam de parcerias entre agroindústria e produtores de animais, nos quais existe o interesse em resguardar a especificidade do ativo das características dos animais para compor a matéria prima que irá para a agroindústria.

Os três contratos têm suas semelhanças e visam garantir a entrega dos animais com certas características que se assemelham às agroindustriais para que se possa garantir um bom aproveitamento das suas carcaças , uma vez que padronização gera qualidade ao produto pela redução de desperdício. Neste sentido, a agroindústria elaborou um contrato para que o produtor rural forneça um bom serviço de manejo, e fica patente na cláusula quarta do contrato o parágrafo único que recomenda o jejum, isto evita o alto índice de mortalidade e as contusões dos suínos, que prejudicam a avaliação das carcaças destes animais. Em caso de negligência dos criadores, estes deverão ressarcir agroindústria. Cabe destacar que existe um grau maior de responsabilidade por parte do produtor que da agroindústria, que faculta menor incerteza para a agroindústria, mas poderá ser fruto de futuros debates e discussões.

No contrato 14 , os animais são suínos, mas há o interesse é obter um padrão de produção de leitões na unidade de produção, cujo processo demanda muitos cuidados para produzir animais sadios e isentos de doenças e deformidades para ter um bom rendimento no crescimento e terminação.

O contrato 17 segue a mesma linha dos anteriores, mas tem uma diferença na especificidade pelo fato de ter em destaque uma cláusula que o torna diferente dos anteriores com relação ao processo de terminação de suínos. No início do contrato existe uma 
série de considerações sobre o caráter social que a organização estabelece com o produtor rural e, na primeira cláusula, trata-o como parceiro cooperado. Nas cláusulas sétima e décima terceira, existe o comprometimento do pecuarista em entregar toda a produção de suínos para a agroindústria, sendo ele o fiel depositário dos animais, podendo entregá-los apenas para a organização agroindustrial definida.

O contrato 26 trata da matéria prima-prima mandioca, mas o modelo multivariado não conseguiu captar o atributo frequência, que é o destaque na salvaguarda.

O contrato 29 trata da franquia de um estabelecimento que irá comercializar cachaça e comida mineira e dispõe de uma série de salvaguardas para atender às especificidades do ativo da franquia. O contrato de fornecimento de cachaça entre franqueado e franqueador tem sua especificidade na exclusividade do ambiente que compõe o bar, restaurante e fornecedores, mas, também nas receitas de drinques e bebidas, as quais devem seguir uma rigorosa norma, isto faz com que haja uma característica, visando sua diferenciação dos demais bares e restaurantes. Ao usar o modelo não foi possível comprovar estas salvaguardas.

Os contratos que tiveram a dimensão 2 (ordenadas)melhor ajustadas no modelo foram, que destacam a frequência:

O contrato 10, que trata sobre as embalagens fornecidas para a agroindústria para servir de invólucro de seus produtos, Neste, observa-se que a salvaguarda está relacionada à frequência intensa que as embalagens deve estar disponíveis sem gerar estoque, um sistema próximo o just in time, as quais devem chegar às unidades de produção da agroindústria para atender às demandas dos pedidos. O período do contrato é de um ano com envio de embalagens de seis em seis meses. Existem cláusulas que obrigam a empresa fornecedora a entregar com uma margem de mais ou menos $10 \%$ da quantidade do pedido, de forma que se ultrapassar esta porcentagem as embalagens serão retornadas à indústria fornecedora de embalagens e os custos serão arcados por ela. Ademais, se faltar embalagens no momento em que a agroindústria estiver necessitando, os custos - "os atrasos - serão penalizados com o repasse dos prejuízos causados pela não entrega na data pactuada". A frequência de entrega foi estabelecida como semanal, podendo este período ser reduzido em caso de emergência, desde que seja discutido caso a caso entre as partes. "Fica acertado também a logística semanal para entrega de embalagens cujos volumes repassados no pedido mensal forem acima de 20.000 unidades. 
O contrato19 de compra e venda de óleo sem refinado tem como cláusula no cronograma a entrega de óleo ao longo de 12 meses, cujo volume mensal está programado em 300 toneladas. No contrato, o descumprimento dos termos da entrega acarretará em uma multa moratória diária de $1 \%$ do valor do óleo não entregue, até $5 \%$ de limite. As mesmas porcentagens estabelecidas como multa serão cobradas se a empresa compradora do óleo se recusar a recebê-lo nos termos do contrato.

Contratos 21 e 24 tratam de promessa de compra e venda de cana-de-açúcar entre a agroindústria e produtor rural nos estados de São Paulo e Minas Gerais. Os contratos buscam, em suas cláusulas, gerar uma frequência moderada na aquisição da matéria-prima (cana-deaçúcar) para a produção de açúcar/álcool pela agroindústria.

Com relação aos contrato 6 nota-se que o período, cujo serviço deve ser executados é objeto de salva guarda, para que a manutenção da agroindústria seja feita dentro do prazo para não prejudicar a produção agroindustrial.

O contrato 9é celebrado entre empresa transportadora e agroindústria, cujo objeto resguardado é o veículo, o qual deve ter qualificações para transporte internacional e ser de uso exclusivo para a agroindústria com uma frequência para o recebimento de carga.

Com relação à incerteza têm-se os seguintes contratos esta no eixo negativo da abcissa:

O contrato 12 trata da aquisição de equipamento nacional para a agroindústria e as cláusulas referem-se à possibilidade de risco, o pagamento que as empresas podem arcar e as obrigações do fornecedor em entregar o equipamento no prazo estabelecido.

No contrato 2 nota-se que o período em que os serviços devem ser executados encaixa-se na tentativa temporal da execução dentro de um período estabelecido, induzindo a mitigar a incerteza da não entrega dos serviço de ampliação do frigorífico.

Os contratos 22 e 23 são contratos de compra e venda de cana-de-açúcar e visam celebrar a redução de incerteza no tocante ao preço desse produto.

Com relação ao contrato 1 são destacadas as salvaguardas que se estabelecem para mitigar a incerteza da aquisição de um equipamento para a agroindústria de aves que é cotada em euros, e as diretrizes contratuais para evitar que a dívida saia do controle da empresa, neste sentido são elaboradas cláusulas para mitigar qualquer incerteza nesta operação para ambas as partes, mas este contrato foi um que o modelo de análise multivariada não conseguiu captar. 
O contrato 5 que trata da exportação de frango segue esta linha de mitigar as incertezas com qualquer problema que possa surgir na venda da mercadoria no mercado internacional. $\mathrm{O}$ segundo contrato que o modelo não consegui captar a o atributo.

Os contratos 3 e 4 tratam da venda de material genético para a agroindústria avícola e pauta-se na minimização das incerteza em suas cláusulas para compor o contrato. Ao analisarem-se os contratos, observa-se que a incerteza é resguardada, pois neles aparecem uma série de salvaguardas que visam atender à demanda da empresa frigorífica, a fim de minimizar os problemas com os animais, os quais deverão ser vacinados contra as doenças de Marek e Bouba, além de garantir a imunidade para uma série de outras doenças (Salmonelas e dos Micoplasmas) com a possibilidade de coleta de amostra para eventuais problemas.

O Contrato 11 visa resguardar a incerteza da a existência de produtos na agroindústria advindos de organismos geneticamente modificados, assim a certificadora irá ajustar seus protocolos com a agroindústria, mas exige rigidez no procedimento para conseguir atender à certificação.

O Contrato 20 que trata do certificado de cédula de produtor rural (cpr) de cana-deaçúcar, cujas salvaguardas exigem que o produtor rural atenda todas as especificações e local para a produção desta matéria-prima. É obrigação do produtor usar os recursos exclusivamente para as atividades "relacionadas ao agronegócio, assim entendidas as atividades relacionadas com a produção, comercialização, beneficiamento ou industrialização de produtos ou insumos agropecuários ou de máquinas e implementos utilizados na atividade agropecuária." Para demonstrar os gastos com as atividades acima destacadas, o produtor deverá comprová-los com notas fiscais de venda do produto decorrentes da atividade de produção de cana-de-açúcar.

Os contratos 27 e 28 de compra e venda de frutas (laranja), descrevem o tipo da laranja (valência, pera rio, natal) que deverá ser comercializada em caixas de 40,8 kg por um período de 4 anos. O produtor deve garantir a entrega integral dos produtos de sua propriedade para a agroindústria, seguindo as especificações quanto à fruta. Não poderá haver refugo superior a $2 \%$ da carga, caso isso ocorra o veículo deverá ficar em um local em que as partes poderão fazer a verificação conjuntamente para não haver assimetria de informação. Outra característica interessante neste contrato é que a determinação do valor a ser pago para o produtor depende do rendimento da fruta que varia com o grau Brix, que é realizado no laboratório da agroindústria, mas caso o produtor não aceite o rendimento da 
fruta estabelecido pela agroindústria poderá contratar um laboratório particular e com os resultados dirimir a dúvida.

Finalizando, os contratos 25, 18 também buscam resguardar a diminuição das incertezas na comercialização de soja, fumo, nas quais o componente incerteza é levado em consideração. No entanto, também o modelo não conseguiu captar este atributo no contrato 18 , que trata do produto fumo.

Nada se pode falar dos contratos 1, 5,18 e 29, uma vez que o modelo da análise fatorial de correspondência informa que ele esta adaptado a um atributo mas na realidade ao ler o contrato este atributo não é observado

\section{Conclusão}

O estudo buscou pela técnica de análise fatorial de correspondência classificar os 29 contratos do agronegócio nas categorias especificidades do ativo, frequência e incerteza. $\mathrm{Na}$ leitura de cada contrato pode-se observar que alguns eram mais bem elaborados que outros. Esse ponto pode ser objeto de pesquisa em futuros trabalhos, uma vez que alguns foram redigidos criteriosamente e outros nem tanto. Isso evidencia que alguns contratos são elaborados apenas como uma mera formalização do negócio ou um documento a mais, mas que não desencadeia uma estrutura de governança com a função de coordenar a transação. Outros apresentam as características de um documento que deve ser seguido como uma lista de informações para que as partes executem-nas dentro do padrão estabelecido.

A estrutura de governança contrato dever ser objeto de estudo das áreas das ciências econômicas, pois tem um campo fértil a ser analisado e promove um melhor entendimento do contrato, é muito discutido na área de direito, mas está engatinhando na economia.

Dos 29 contratos analisados em 5 deles não houve possibilidade da análise fatorial evidenciar os atributos apontados.

Os contratos, neste estudo, foram classificados nas três categorias supracitadas, mas outras podem ser utilizadas para melhor classificar e qualificar os vários tipos de contratos que são assinados cotidianamente dentro do agronegócio.

\section{REFERÊNCIAS}

ARAÚJO, F. Teoria Econômica do Contrato. Coimbra: Almedina. 2007.

BODINI, V. L.; ROCHA JR, W. F., FIÚZA SOBRINHO, R. ANÁLISE DE CONTRATOS

R. Bras. Planej. Desenv., Curitiba, v. 4, n. 2, p. 94-118, jul./dez. 2015 
AGROINDUSTRIAIS e o uso da ESTATÍSTICA MULTIVARIADA. In. XLIX Congresso Brasileiro de Economia e Sociologia Rural, Belo Horizonte, 2011. Anais..., SOBER. CD- ROM.

BENZÉCRI, J. P. et al. L'analyse des donnés. Tome II. L'analyse des correspondances. Paris: Dunod, 1973. 635 p.

BOUROCHE, J. M.; SAPORTA, G. Análise de dados. Rio de Janeiro: Zahar, 1982. 117 p.

CAMARGO, C. C. B. Gerenciamento pelo lado da demanda: metodologia para identificação do potencial de conservação de energia elétrica de consumidores residenciais. Florianópolis, 1996, p. 197. Tese (Doutorado) - Universidade Federal de Santa Catarina. Programa de Pós-graduação em Engenharia de Produção.

CARROL, J. D.; GREEN, P. E. An INDSCAL-Based approach to multiple correspondence analysis. Journal of Marketing Research. v. XXV, May, 1988, p. 193-203.

CARROL, J. D.; GREEN, P. E; SCHAFFER, M. C. Interpoint distance comparisons in correspondence analysis. Journal of Marketing Research.v. XVI, August, 1986. p. 271-280.

CARROL, J. D.; GREEN, P. E; SCHAFFER, M. C. Reply to Greenacre's commentary on the Carrol- Green-Schaffer scalling of two-way correspondence analysis solutions. Journal of Marketing Research. v. XXVI, August, 1989. p. 366-368.

COASE, R. H. The firm, the market and the law. Chicago: University of Chicago Press, 1988. 217 p. .The nature of the firm. In: WILLIAMSON, O.; WINTER, S. G. (Ed.) In the nature of the firmorigins, evolution and development. New York: Oxford University Press, 1993. $256 \mathrm{p}$.

. The New Institutional Economics. American Economics Review, Nashville, v. 88,

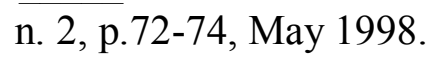

The problem of social costs. Journal of Law and Economics, Chicago, v.3.,n.1, p.144, Out.1960.

CORDEIRO,A. M. R.,M, Da boa-fé no Direito Civil.Lisboa: Almedina, 1983.

DAVIS, J. H.; GOLDBERG, R. A. A concept of agribusiness. Boston: Harvard University, Graduate School of Business Administration, 1957, p. 136.

FARINA, E. M. M. Q. Competitividade e coordenação de sistemas agroindustriais: um ensaio conceituai. Gestão \& Produção, São Carlos, v. 6, n. 3, p. 147-161, dez. 1999.

FARINA, E. M. M. Q.; ZEVEDO, P. F.; SAES, M. S. M. Competitividade: mercado, estado e organizações. São Paulo: Editora Singular, 1997.

FIÚZA SOBRINHO et al. ANÁLISE DOS CONTRATOS NA AVICULTURA DE CORTE: O CASO DE UMA COOPERATIVA DO OESTE DO PARANÁ. In. XLVII 
Congresso Brasileiro de Economia e Sociologia Rural, Porto Alegre, 2009. Anais..., SOBER. CD-ROM. 2009.

FUKUNAGA, K; HUFFMAN, W. The role of risk and transaction costs in contract design: evidence from farmland lease contracts in U.S. agriculture. American Journal of Agricultural Economic, Milwaukee, v.91, n.1, p. 237-249, feb. 2009.

GREENACRE, M. J. The Carrol-Green-Schaffer scaling in correspondence analysis: a theoretical and empirical appraisol. Journalof Marketing Research. v. XXVI, p. 358-365 August, 1989...

GIL, A. C. Técnicas de pesquisas em economia e elaboração de monografias. 3 ed. São Paulo: Atlas, 2000, p.217.

GOMES, O. Contratos. 20 ed. São Paulo: Forense Jurídica. 2002

HOFFMAN, D. L.; FRANKE, G. R. Correspondence analysis: graphical representation of categorical data in marketing research. Journal of Marketing Research. v. XXIII, August, 1986, p. 213-217.

KAVLOY, O.; OLSEN T. E. Endogenous verifiability and relational contracting. American Economic Review, Pittsburgh, v.99, n.5, p. 2193-2208. 2009

KACIAK, E.; LOUVIERE, J. Multiple correspondence analysis of multiple choice experiment data. Journalof Marketing Research. v. XXVII, November, 1990, p. 455-465.

LUPION, R. Boa-fé objetiva nos contratos empresariais: contornos dogmáticos dos deveres de conduta. Porto Alegre: Livraria do advogado. 2011.

MCDONALD, J.; PERRY, J.; AHEARN, M.; BANKER, D.; CHAMBERS, W.; DIMITRI, C.; KEY, N.; NELSON, K.; SOUTHARD, L. Agriculture economic report no. 837. United States of Departament of Agriculture. Nov. 2004. Disponível em: $<$ http://www.ers.usda.gov/publications/aer837/>. Acesso em: 06 jan. 2011.

MORVAN, R. P. et al. Técnicas de análise multivariada. São Paulo: UNICAMP, 1996. (Apostila da disciplina Análise de Multivariada). 1996.

NOGUEIRA, A. C. L. Custos de transação e arranjos institucionais alternativos: uma análise da avicultura de corte no Estado de São Paulo. 153 f. São Paulo, 2003. Universidade de São Paulo, Faculdade de Economia, Administração e Contabilidade - USP. 2003.

NORONHA, F. O Direito nos contratos e seus princípios e fundamentos. São Paulo: Saraiva 1994.

NORTH, D. Custos de transação, instituições e desempenho econômico. Rio de Janeiro: Instituto Liberal, 1994, p. 38.

OLIVEIRA, C. A. C. N. V. O surgimento das estruturas híbridas de governança na 
indústria de energia elétrica no Brasil: a abordagem institucional da economia dos custos de transação. 1998. 207 f. Dissertação (Mestrado) - Departamento de Ciências Econômicas, Universidade Federal de Santa Catarina, Florianópolis. 1998.

RODRIGUES, R. O agronegócio brasileiro. Belo Horizonte, 2004 (Palestra apresentada no Seminário Desafios de Logística para o Agronegócio). 2004.

RIBEIRO, M. C.; GALESKI JÚNIOR, I. Teoria Geral dos contratos: contratos empresariais e análise econômica. Rio de Janeiro: Elsevier. 2009.

ROCHA JR, W. F.; RIBEIRO, M. C. P. Institutional environment and contracts: a case study in the agroindustrial system of broiler factory farming in the west of the state of Paraná, Brazil. In: Annual Conference of Italian Society of Law and Economics, 7., 2011, Turim. Proceeding...,Turim: ItalianSociety of Law and Economics. p. 14-28. Disponível em: $<$ http://www.side- isle.it/ocs2/index.php/SIDE/side-isle2011/paper/view/718>. Acesso em: 20/06/2012.

ROCHA JR et al. Contratos: uma abordagem pela ótica da nova economia institucional. Parceria no processo de terminação de frangos de corte no estado do Paraná/Brasil. In: RIBEIRO, M. C. P.; KLEIN, V. O que é Análise Econômica do Direito: uma introdução. Belo Horizonte: editora Forum. 2011. Cap13. p. 151-157.

ROPPO, E. O contrato. Almeida: Coimbra. 1977.

SALAMA, B. M. Vetores da jurisprudência na interpretação dos contratos bancário. Revista de Direito Bancário e no Mercado de Capitais, São Paulo, v.57, p.157-170. 2012.

SALOMÃO FILHO, C. Função social do contrato: primeiras anotações. Revista dos Tribunais, São Paulo, v.823, ano 93, p. 67- 86, maio, 2004.

SILVA, E.; VERTINELLI, M. A. Avaliação em massa de terrenos em Blumenau (Santa Catarina - Brasil) usando análise fatorial de correspondência e regressão múltipla. Santa Catarina: Universidade Federal de Santa Catarina, n. 09/97. Outubro 1997.

TIROLE, J. Cognitionandincomplitecontracts. American Economic Review, Pittsburgh, v.99, n.1, p. 265-294. Mar. 2009.

VERDINELLI. M. A. Análise inercial em ecologia. 1980. 162 f. Tese (Doutorado em Ciências Biológicas) - USP, São Paulo. 1980.

ZYLBERSZTAJN, D. A estrutura de governança e coordenação do agribusiness: uma aplicação da nova economia das instituições. 1995. 238 f. Tese (Livre-Docência) Faculdade de Economia, Administração e contabilidade, Universidade de São Paulo, São Paulo. 1995.

ZYLBERSZTAJN, D; SZTAJN, R. Direito \& Economia: Análise econômica do direito e das organizações. Rio de Janeiro: ELSEVIER. 2005. 
WILliamSON, O. E. The Lens of Contract: Private Ordering. American Economic Review, Nashville, v.92, n.2, p.438-433, may, 2002.

The new institutional economics: taking stock, looking ahead. Journal of EconomicLiterature, Stanford, v. 38, n. 3, p. 595-613, Sep. 2000.

. The mechanism of governance. New York: Oxford University Press, 1996. 429 p.

The economic institutions of capitalism. New York: Free Press, 1985. 450 p.

The modern corporation: origins, evolution, and attributes. Journal of Economic Literature,Stanford, v. 19, n. 4, p. 1537-1568, Dec. 1981.

Transaction-cost economics: the governance of contractual relations. Journal ofLaw and Economics, Chicago, v. 22, n. 2, p. 233-261, Oct. 1979.

ZYLERSZTAJN, D. Papel dos Contratos na Coordenação Agro-Industrial: um olhar além dos mercados. Revista de Economia e Sociologia Rural, Rio de Janeiro, v.45, n. 3, p. 385-429, jul./set. 2005.

Recebimento dos originais: 25/09/2015

Aceitação para publicação: 09/11/2015 